Canadian

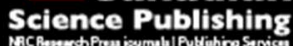

Applied Physiology, Nutrition, and Metabolism Physiologie appliquée, nutrition et métabolisme

\title{
Vitamin D status is not related to insulin resistance in different phenotypes of moderate obesity
}

\begin{tabular}{|c|c|}
\hline Journal: & Applied Physiology, Nutrition, and Metabolism \\
\hline Manuscript ID & apnm-2016-0298.R2 \\
\hline Manuscript Type: & Article \\
\hline Date Submitted by the Author: & 09-Nov-2016 \\
\hline Complete List of Authors: & $\begin{array}{l}\text { Al Masri, Manal; Centre Hospitalier Regional Universitaire de Montpellier, } \\
\text { Endocrinology-Diabetology-Nutrition } \\
\text { Romain, Ahmed; University of Montreal Hospital Research Centre, } \\
\text { Boegner, Catherine; Centre Hospitalier Regional Universitaire de } \\
\text { Montpellier, Endocrinology-Diabetology-Nutrition } \\
\text { Maimoun, Laurent; Groupe de Recherche Interdisciplinaire sur le } \\
\text { M-tabolisme Osseux (GRISMO); Centre Hospitalier Regional Universitaire } \\
\text { de Montpellier; Inserm U1046 } \\
\text { Mariano-Goulart, Denis; Centre Hospitalier Regional Universitaire de } \\
\text { Montpellier; Inserm U1046 } \\
\text { Attalin, Vincent; Centre Hospitalier Regional Universitaire de Montpellier, } \\
\text { Endocrinology-Diabetology-Nutrition } \\
\text { Leprieur, Elodie; Centre Hospitalier Regional Universitaire de Montpellier, } \\
\text { Endocrinology-Diabetology-Nutrition } \\
\text { Picandet, Marion; Centre Hospitalier Regional Universitaire de Montpellier, } \\
\text { Endocrinology-Diabetology-Nutrition } \\
\text { Avignon, Antoine; Centre Hospitalier Regional Universitaire de Montpellier, } \\
\text { Endocrinology-Diabetology-Nutrition ; Inserm U1046 } \\
\text { Sultan, Ariane; Centre Hospitalier Regional Universitaire de Montpellier, } \\
\text { Endocrinology-Diabetology-Nutrition ; Inserm U1046 }\end{array}$ \\
\hline Keyword: & $\begin{array}{l}\text { obesity, insulin resistance < metabolic syndrome, metabolism, body } \\
\text { composition }\end{array}$ \\
\hline
\end{tabular}

\section{SCHOLARONE \\ Manuscripts}


Vitamin D status is not related to insulin resistance in different phenotypes of moderate obesity

Running head: relationships between 25OHD and metabolic parameters in moderate obesity

Manal Al Masri ${ }^{1 *}$, Ahmed Jerome Romain ${ }^{1 *}$, Catherine Boegner ${ }^{1}$, Laurent Maimoun ${ }^{2,3}$, Denis Mariano-Goulart ${ }^{2}$, Vincent Attalin ${ }^{1}$, Elodie Leprieur ${ }^{1}$, Marion Picandet ${ }^{1}$, Antoine Avignon $^{1,3}$, Ariane Sultan ${ }^{1,3}$

1 Département Endocrinologie, Nutrition, Diabète, Equipe Nutrition, Diabète, CHRU Montpellier, Montpellier, France.

²Département de Médecine Nucléaire, CHRU Montpellier, Montpellier, France.

${ }^{3}$ U1046 INSERM, UMR9214 CNRS, Physiologie et Médecine Expérimentale du Cœur et des Muscles, University of Montpellier, CHRU Montpellier, France..

* These authors contributed equally to this work

\section{Corresponding author}

A. Sultan, a-sultan@chu-montpellier.fr

Phone: +33467338402

Endocrinology-Diabetes-Nutrition Department

Unit of Nutrition-Diabetes

University Hospital of Montpellier

Montpellier, France 


\begin{abstract}
:
Background/Objectives: Low plasma 25-hydroxy-vitamin D (25OHD) and high levels of parathyroid hormone $(\mathrm{PTH})$ are associated with obesity and could play a role in the occurrence of its complications such as insulin resistance. The objective of the study was to evaluate whether the relationship between 25OHD status and phosphocalcic parameters differ between metabolically healthy obese (MHO) and insulin-resistant obese (IRO).
\end{abstract}

Subjects/Methods: Cross-sectional study including 158 consecutive adults (121 females) with obesity (BMI $35.15 \pm 2.8 \mathrm{~kg} / \mathrm{m}^{2}$ ), age $43.21 \pm 13.6$ years. Serum $25 \mathrm{OHD}$, calcemia, phosphatemia, PTH, plasma lipids, fasting plasma glucose, insulin levels and body composition were measured.

Results: Participants were classified as MHO $(n=65)$ or IRO $(n=93)$ based on HOMA-IR value. IRO patients had higher BMI $(\mathrm{p}=0.001)$, waist circumference $(\mathrm{p}=0.03)$, and trunk fat mass $(p=0.007)$ than MHO patients. Mean HbA1c $(p=0.03)$, triglycerides $(p=0.02)$, and hsCRP $(\mathrm{p}=0.04)$ plasmatic levels were increased in the IRO group. No between-groups difference was found on $25 \mathrm{OHD}$, $\mathrm{PTH}$, calcium or phosphorus plasmatic levels. Regarding predictive factors of 25OHD, only age predicted 25OHD level among IRO participants while no factors were identified in MHO. No predictive factors of PTH plasmatic level were identified in IRO and MHO groups.

Conclusions: Although MHO and IRO patients have different metabolic profiles, we did not detect any difference regarding either $25 \mathrm{OHD}$ or PTH. IR was not a predictive factor of vitamin D status. Our results confirm the absence of link between vitamin D status and IR in moderate obesity.

Keywords: obesity, insulin resistance, metabolism, body composition 


\section{Introduction}

Obesity is well recognized as a global epidemic (Popkin 2010) and is associated with various co-morbidities, including hypertension, insulin resistance (IR) and other components of the metabolic syndrome (Botella-Carretero et al. 2007, Kayaniyil et al. 2011). Obesity and its complications significantly contribute to modern healthcare costs, morbidity and mortality (Wang et al. 2008, Yach et al. 2006). Further, mechanisms involved in IR are not fully understood.

Over the past years, several abnormalities in the regulation of mineral metabolism, including vitamin D deficiency (Bell et al. 1985, Buffington et al. 1993) and increased levels of parathyroid hormone (PTH) (Adam et al. 2010, Bolland et al. 2005, Kamycheva et al. 2004), have been reported in obese individuals. They have been associated with IR (Chiu et al. 2004, Deleskog et al. 2012, Reis et al. 2007,), systemic inflammation (Sukumar et al. 2011), arterial calcifications (Gilardini et al. 2011), and presence of metabolic syndrome components (Hjelmesaeth et al. 2009). However, it is not clear whether the observed low vitamin D and high circulating PTH levels in obese individuals can further and independently contribute to the risk of developing metabolic diseases or whether they should be considered as a disturbance of mineral metabolism per se. Indeed, the question of the relationships between anthropometric, metabolic factors and vitamin D status remains partly unanswered. Crosssectional studies showed correlations between the aforementioned factors (Bellia et al. 2012, Hjelmesaeth et al. 2009,). Indeed, one study recently showed that among class III obesity, metabolically healthy obese patients (MHO) had higher levels of 25OHD than insulinresistant obese (IRO), with comparable levels of circulating PTH (Bellia et al. 2012). This study further showed an independent inverse association between 25OHD and insulin resistance in both $\mathrm{MHO}$ and IRO patients. On the opposite, interventional studies using vitamin D supplementation have yielded conflicting results, reporting either a decreased IR 
(Nagpal et al. 2009, Von Hurst et al. 2010) or no effect (Jorde and Figenschau 2009, Wamberg et al. 2013).

Therefore, our objective was to evaluate whether the relationship between vitamin D status and phosphocalcic parameters differs between $\mathrm{MHO}$ and IRO patients, suffering from moderate class I obesity, in order to determine if vitamin D status could be associated with IR.

\section{Material and Methods:}

\subsection{Patients and methods}

\subsubsection{Inclusion and exclusion criteria}

Obese patients referred to our department for metabolic and physical assessment of their obesity were assessed for eligibility. Inclusion criteria were age $<65 \mathrm{y}, \mathrm{BMI}>30$, no calcium or vitamin D supplementation, no past bariatric surgery

Patients with known diabetes mellitus were excluded $(\mathrm{HbA1c}>6.5 \%$; fasting plasmatic glycemia $>7 \mathrm{mmol} / \mathrm{l}$ and/or presence of any anti-diabetic medications). Participants over 65 years old were also excluded. All participants had normal cardiopulmonary and kidney functions as determined by medical history, physical examination, creatinine clearance calculation and electrocardiogram realized by one investigator of the study. Height and weight were measured wearing light clothing and no shoes; BMI was calculated as weight in $\mathrm{kg}$ divided by the square of height in meters $\left(\mathrm{kg} / \mathrm{m}^{2}\right)$. Waist circumference was recorded to the nearest $0.1 \mathrm{~cm}$ midway between the last rib and the crest of the ileum using a non-stretch tape measure on lightly clad participants.

\subsection{Patients consent:}

All participants gave written informed consent. The study was performed according to the principles of the Declaration of Helsinki and was approved by the local ethics committee. All 
patients were entered into a registry with data collected from their hospitalization including anthropometric, clinical and biological information ( $\left.\mathrm{N}^{\circ} \mathrm{DC}-2009-1052\right)$.

\subsection{Laboratory procedures:}

Blood was drawn in the morning after an 8-hour overnight fast. Fasting plasma glucose (FPG) was measured by routine biochemistry analysis. Total and high-density lipoprotein (HDL) cholesterol were measured by routine enzymatic methods (KonePro; Konelab, Epoo, Finland). Low-density lipoprotein (LDL) cholesterol was calculated according to the Friedwald formula. Hemoglobin A1c (HbA1c) was measured with routine high-performance liquid chromatography (HPLC)-based ion-exchange procedure (HA-8140; Menarini, Rungis Cedex, France). Hormones (insulin and PTH) were measured by technique ECLIA Electroluminescence, and 25OHD by the CLIA method (Elecsys; Roche, France).

Vitamin D deficiency was defined as plasma levels $<50 \mathrm{nmol} / 1(20 \mathrm{ng} / \mathrm{ml})$ in agreement with current guidelines (Holick et al. 2011). Hyperparathyroidism was defined as plasmatic PTH concentration $>62 \mathrm{pg} / \mathrm{ml}$, regarding laboratory standard.

All patients underwent oral glucose tolerance test (OGTT) using a load of $75 \mathrm{~g}$ of glucose. The results were evaluated according to ADA criteria as diabetes mellitus, impaired fasting glucose, and impaired glucose tolerance (American Diabetes Association 2010). The Homeostatic Model Assessment index-insulin resistance (HOMA-IR) value was calculated as follows: fasting insulin $\times$ fasting glucose $/ 22.5$. Using a stratification based on HOMA-IR, 2 sub-groups were defined: IRO (HOMA-IR values were $\geq 3$ ) and MHO sub-groups (HOMAIR values were $\leq 3$ ) (Matthews et al. 1985).

Each participant underwent a total body scan using dual-energy x-ray absorptiometry (DXA) (Dual Energy X-ray absoptiometry, Hologic QDR 4500 A.).

\subsection{Statistical analyses:}


Statistical analysis was performed between MHO and IRO groups.

To analyze the differences between groups, one-way ANOVA was performed on the different selected outcomes. Then, to obtain the effect size of the between-group difference, cohen's $d$ was computed and by convention, $0.2,0.5$ and 0.8 represent small, medium, and large effect, respectively. To detect predictive factors of $25 \mathrm{OHD}$ and $\mathrm{PTH}$ plasmatic levels, multiple regression analysis was carried out. The multiple regression analyses were conducted among the entire sample, and separately in the MHO and IRO sample, respectively. The independent variables were hsCRP, Fasting glucose, 2-h glucose, fasting insulin and were selected on the basis of a previous study (Bellia et al. 2012). Only age was added to control for its effect. Significance effect was set at 0.05 . Statistical analyses were performed with Statistica 7.1 (Statsoft france).

\section{Results:}

A total of 158 consecutive patients were included, of which 65 IRO and 93 MHO patients. Seventy-six percent of the patients enrolled were female. Nonetheless, the proportion of females did not differ between groups $(\mathrm{p}=0.49)$.

\subsection{Anthropometric and metabolic parameters of MHO and IRO patients}

Main clinical and metabolic characteristics of MHO and IRO patients are reported in Table 1. The MHO group had lower trunk fat $(19.97 \pm 4.24 \mathrm{~kg} v s .22 .23 \pm 6.04 \mathrm{~kg} ; \mathrm{p}=0.007)$, along with lower BMI values $\left(34.57 \pm 2.69 \mathrm{~kg} / \mathrm{m}^{2}\right.$ vs $\left.35.98 \pm 2.78 \mathrm{~kg} / \mathrm{m}^{2} ; \mathrm{p}=0.001\right)$ and lower waist circumference $(106.25 \pm 10.18 \mathrm{~cm}$ vs $109.93 \pm 10.30 \mathrm{~cm} ; \mathrm{p}=0.03)$ compared to IRO patients. Mean age tended to be higher in MHO patients ( $\mathrm{p}=0.08)$. In addition, MHO individuals exhibited lower levels of fasting glucose $(\mathrm{p}=0.0001)$, 2-h post load glucose $(p=0.001)$ and triglycerides $(p=0.02)$, whereas plasmatic level of total 
cholesterol, HDL cholesterol and LDL cholesterol did not differ between groups. As markers of systemic inflammation, circulating levels of hsCRP were significantly reduced in $\mathrm{MHO}$ compared to IRO patients $(\mathrm{p}=0.04)$. Furthermore, $19 \%$ of $\mathrm{MHO}$ patients were taking antihypertensive agents compared with $25 \%$ of IRO patients.

3.2 Mineral metabolism-related parameters in MHO and IRO patients Mean 25OHD plasmatic levels were not different between the two sub-groups $(19.50 \pm 8.11$ $\mathrm{ng} / \mathrm{ml}$ in MHO vs. $21.94 \pm 9.69 \mathrm{ng} / \mathrm{ml}$ in IRO; $\mathrm{p}=0.11)$ (Table 1). Similarly, PTH plasmatic concentrations did not differ between the 2 sub-groups $(37.45 \pm 24.35 \mathrm{ng} / \mathrm{L}$ in $\mathrm{MHO}$ vs 31.97 $\pm 13.69 \mathrm{ng} / \mathrm{L}$ in IRO; $\mathrm{p}=0.13$ ). In the whole cohort, the resulting proportion of patients with vitamin D deficiency was about $47.36 \%(n=81)$ and was substantially smaller in IRO patients $(40.74 \% ; \mathrm{n}=33)$ than in MHO patients $(59.26 \% ; \mathrm{n}=48)(\mathrm{p}=0.16)$. Moreover, we found that $86 \%(n=41)$ of the MHO sub-group had a Vitamin D deficiency without hyperparathyroidism compared to $96 \%(\mathrm{n}=31)$ in the IRO group $(\mathrm{p}=0.34)$. Circulating levels of calcium, phosphorus and bone mineral density (BMD) were similar between the two sub-groups, as displayed in Table 1.

\subsection{Predictive factors of 25OHD and PTH plasmatic levels}

All coefficients of regression with their standard errors and their $\mathrm{p}$ value are provided in Table 2 (MHO patients), table 3 (IRO patients) and supplementary table S1 file 1 (entire population).

Regarding 25OHD plasmatic level, the regression model was not significant for the entire sample size $[\mathrm{F}(5,152)=0.93 ; \mathrm{p}=0.46]$ or the $\mathrm{MHO}$ group; $[\mathrm{F}(5,87)=0.35 ; \mathrm{p}=0.87]$. Concerning the IRO patients, the model of regression was very close to the significance 
threshold $[\mathrm{F}(5,59)=1.95 ; \mathrm{p}=0.051]$ with a $\mathrm{R}^{2}$ of 0.16 . Through the dependant variable, only age was positively and significantly associated with 25OHD plasmatic level $(p=0.005)$.

The same analysis was performed for PTH plasmatic level. Among IRO participants, albeit hsCRP was negatively associated with level of PTH $(\mathrm{p}=0.04)$, the final regression model was not significant $[F(5,59)=1.55 ; \mathrm{p}=0.18]$. The final model of regression was not significant in the MHO group $[\mathrm{F}(5,87)=0.79 ; \mathrm{p}=0.55]$ and in the entire population $[\mathrm{F}(5,152)=0.72 ; \mathrm{p}=$ $0.60]$.

\section{Discussion}

We demonstrated in this cross-sectional study including grade 1 obese patients with two different phenotypes of obesity that 1) MHO patients and IRO patients have comparable plasmatic levels of 25OHD, calcium, phosphorus and PTH, 2) in IRO patients, only age was associated with 25OHD plasmatic levels, 3) metabolic parameters did not predict PTH plasmatic levels in both groups.

It is largely known that individuals with obesity have lower levels of $25 \mathrm{OHD}$ than people from the general population (Chapuy et al. 1997, Hyppönen and Power 2007). It has already been reported that 25OHD deficiency concerns $85 \%$ of obese subjects (Hyppönen and Power 2007) comparatively to $30 \%$ to $50 \%$ of the general population (Holick et al. 2011). In our cohort, this prevalence was $47 \%$, which is below the aforementioned prevalence among people with obesity. This difference could be explained by the geographical location and moderate obesity of our included patients. Regarding increased prevalence of vitamin D deficiency during obesity, it may be explained by several mechanisms. Higher amount of abdominal fat has been reported to contribute mostly to the adipose tissue sequestration of 25OHD (Arunabh et al. 2003, Vilarrasa et al. 2007). This mechanism could partly explain the lower prevalence we found compared to more severe obesity. Other mechanisms such as 
nutritional deficiency due to dietary restriction, or lower sun exposure can also be evocated (Hyppönen and Power 2007).

Regarding the association between levels of Vitamin D and IR, we showed that MHO and IRO patients had comparable circulating 25OHD. On the contrary, a recent study from Bellia et al. showed that 25OHD plasmatic levels were higher in MHO than in IRO with 174 subjects (Bellia et al. 2012). This discrepancy could be explained by some methodological considerations. Firstly, the two samples had different BMI: the mean BMI of included participants was $45 \mathrm{~kg} / \mathrm{m}^{2}$ (class III obesity) in the Belia's study while it was $35.15 \pm 2.8 \mathrm{~kg} / \mathrm{m}^{2}$ (class I obesity) in ours. As previously explained, the adipose tissue is highly associated with vitamin D regulation and higher BMI is associated with higher adipose tissue. Secondly, their patients were less than 50 years old, while our exclusion criterion regarding age was set at 65 years old. Thus, this inclusion criterion may explain that age was positively and significantly associated with $25 \mathrm{OHD}$ in the IRO group. In fact, albeit reasons are unclear, age is known to be associated with 25OHD levels (Lagunova et al. 2009) even though it remains a negligible factor compared to BMI or PTH (Bischof et al. 2006). Nonetheless, another study seems to corroborate the absence of differences in 25OHD levels in more severe form of obesity associated with metabolic syndrome (Hjelmesaeth et al. 2009). A clarification could be obtained from a review highlighting that Vitamin D supplementation decreases IR only when the Vitamin D bioavailability is considered as normal (> $50 \mathrm{nmol} / \mathrm{l})$ (Poolsup et al. 2016). Therefore, this may partly explain the lack of association in our sample given that almost half of our participants had a Vitamin D deficiency (Poolsup et al. 2016).

Furthermore, our results are in agreement with most studies evaluating effects of vitamin D supplementation on IR, which mainly gave negative results in adults, arguing for an absence of link concerning the role of $25 \mathrm{OHD}$ in IR. Indeed, Mason et al. did not find this benefits 
with a 12-month supplementation among post-menopausal women, aged between 50 to 75 , involved in a weight loss program (Mason et al. 2014). Similarly, another study carried out among African American reported no effects of a three-month supplementation on post-load glucose (Harris et al. 2012). In the same vein, supplementation was again without added benefits on IR (measured by the HOMA-IR and by the 2-h post-load glucose) in healthy overweight women (Salehpour et al. 2013). In fact, these set of research are corroborated by a meta-analysis showing no overall effects of the supplementation on IR (George et al. 2012). Nevertheless, this meta-analysis showed that the sub-group of patients with an abnormal glucose tolerance could benefit from this supplementation (George et al. 2012). This is further supported by Kelishadi et al. who reported a reduction in IR (measured by the HOMA-IR) in obese (pre-)adolescents after a three-month vitamin D supplementation (Kelishadi et al. 2014)

Furthermore, mean plasmatic PTH levels or BMD did not differ between groups. Further, we found that $88 \%$ of MHO had a vitamin D deficiency without elevated PTH, compared to $96 \%$ in the IRO group. Nevertheless, blunted PTH response in the presence of vitamin D deficiency is not readily apparent (Kamycheva et al. 2003). Indeed, dysfunction of the parathyroid glands such as abnormalities of the parathyroid calcium sensing receptor, or abnormalities of the $1,25(\mathrm{OH}) 2 \mathrm{D}$ receptor, or even less common causes such as abnormal expression of growth repressing genes within the gland could be involved (Kamycheva et al. 2003). Another hypothesis is that obese people have elevated levels of circulating estrogens (Schindler et al. 1972), which is known to suppress RANK ligand-induced osteoclast differentiation (Shevde et al. 2000) and to increase $1 \alpha$-hydroxylase activity which stimulates 25OHD conversion into $1,25(\mathrm{OH}) 2 \mathrm{D}$, leading to the inhibition of $\mathrm{PTH}$ and thus to decreased bone turnover (Tanaka et al. 1976). 
Finally, some study limitations should be acknowledged, mainly related to the cross-sectional design that did not allow us to assess any causal relationships and to the small sample size that precludes stratifying the sample by subgroups to evaluate a hypothetical threshold effect. Then, information is lacking regarding dietary vitamin D intake, weight history and duration of sun exposure. In addition we did not assess urinary calcium excretion or bone turnover markers, which would have been useful to better characterize the regulation of mineral metabolism in our patients. Last, we assessed IR with HOMA-IR, easily measured in routine, and not with the euglycemic hyperinsulinemic clamp.

\section{Conclusion}

In conclusion, even though MHO and IRO patients have different metabolic profiles, we did not detect any difference regarding either plasmatic Vitamin D concentration or PTH level. Furthermore, in IRO the only dependent variable associated with $25 \mathrm{OHD}$ level was age. Thus, in view of the negative results of vitamin D supplementation on IR (Gagnon et al. 2014, Poolsup et al. 2016), our study reinforces the absence of link between vitamin D status and insulin resistance in moderate obesity. Future studies should use cluster randomized controlled design to analyze whether a more aggressive 25OHD supplementation among overweight individuals with normal levels of 25OHD would have effects on IR

\section{Author Contributions:}

CB, VA, EL, MP, AS and AA: patients' recruitment. MA, AJR, AS and AA: patients' inclusion, data collection. LM, DMG, AS, biological analyses. MA, AJR, AS: interpretation of data, writing manuscript.

We thank Valerie Macioce for English corrections. 
The authors have no relevant conflict of interest to disclose.

\section{Conflict of interest statement}

None to disclose with the present study 


\section{References:}

Adam, M.A., Untch, B.R., Danko, M.E., Stinnett, S., Dixit, D., Koh, J., et al. 2010. Severe obesity is associated with symptomatic presentation, higher parathyroid hormone levels, and increased gland weight in primary hyperparathyroidism. J. Clin. Endocrinol. Metab. 95(11): 4917-4924. doi:10.1210/jc.2010-0666.

American Diabetes Association. 2010. Diagnosis and classification of diabetes mellitus. Diabetes Care 33 Suppl 1: S62-69. doi:10.2337/dc10-S062.

Arunabh, S., Pollack, S., Yeh, J., and Aloia, J.F. 2003. Body fat content and 25-hydroxyvitamin D levels in healthy women. J. Clin. Endocrinol. Metab. 88(1): 157-161. doi:10.1210/jc.2002-020978.

Bell, N.H., Epstein, S., Greene, A., Shary, J., Oexmann, M.J., and Shaw, S. 1985. Evidence for alteration of the vitamin D-endocrine system in obese subjects. J. Clin. Invest. 76(1): 370-373.

doi:10.1172/JCI111971.

Bellia, A., Marinoni, G., D’Adamo, M., Guglielmi, V., Lombardo, M., Donadel, G., et al. 2012. Parathyroid hormone and insulin resistance in distinct phenotypes of severe obesity: a crosssectional analysis in middle-aged men and premenopausal women. J. Clin. Endocrinol. Metab. 97(12): 4724-4732. doi:10.1210/jc.2012-2513.

Bischof, M.G., Heinze, G., and Vierhapper, H. 2006. Vitamin D status and its relation to age and body mass index. Horm. Res. 66(5): 211-215. doi:10.1159/000094932.

Bolland, M.J., Grey, A.B., Gamble, G.D., and Reid, I.R. 2005. Association between primary hyperparathyroidism and increased body weight: a meta-analysis. J. Clin. Endocrinol. Metab. 90(3): 1525-1530. doi:10.1210/jc.2004-1891.

Botella-Carretero, J.I., Alvarez-Blasco, F., Villafruela, J.J., Balsa, J.A., Vázquez, C., and EscobarMorreale, H.F. 2007. Vitamin D deficiency is associated with the metabolic syndrome in morbid obesity. Clin. Nutr. Edinb. Scotl. 26(5): 573-580. doi:10.1016/j.clnu.2007.05.009.

Buffington, C., Walker, B., Cowan, G.S. Jr, and Scruggs, D. 1993. Vitamin D Deficiency in the Morbidly Obese. Obes. Surg. 3(4): 421-424. doi:10.1381/096089293765559142.

Chapuy, M.C., Preziosi, P., Maamer, M., Arnaud, S., Galan, P., Hercberg, S., et al. 1997. Prevalence of vitamin $D$ insufficiency in an adult normal population. Osteoporos. Int. J. Establ. Result Coop. Eur. Found. Osteoporos. Natl. Osteoporos. Found. USA 7(5): 439-443.

Chiu, K.C., Chu, A., Go, V.L.W., and Saad, M.F. 2004. Hypovitaminosis D is associated with insulin resistance and beta cell dysfunction. Am. J. Clin. Nutr. 79(5): 820-825.

Deleskog, A., Hilding, A., Brismar, K., Hamsten, A., Efendic, S., and Östenson, C.-G. 2012. Low serum 25-hydroxyvitamin $D$ level predicts progression to type 2 diabetes in individuals with prediabetes but not with normal glucose tolerance. Diabetologia 55(6): 1668-1678. doi:10.1007/s00125-012-2529-x.

Gagnon, C., Daly, R.M., Carpentier, A., Lu, Z.X., Shore-Lorenti, C., Sikaris, K., et al. 2014. Effects of combined calcium and vitamin $D$ supplementation on insulin secretion, insulin sensitivity and $\beta$-cell 
function in multi-ethnic vitamin D-deficient adults at risk for type 2 diabetes: a pilot randomized, placebo-controlled trial. PloS One 9(10): e109607. doi:10.1371/journal.pone.0109607.

George, P.S., Pearson, E.R., and Witham, M.D. 2012. Effect of vitamin D supplementation on glycaemic control and insulin resistance: a systematic review and meta-analysis. Diabet. Med. J. Br. Diabet. Assoc. 29(8): e142-150. doi:10.1111/j.1464-5491.2012.03672.x.

Gilardini, L., Pasqualinotto, L., Di Matteo, S., Caffetto, K., Croci, M., Girola, A., et al. 2011. Factors associated with early atherosclerosis and arterial calcifications in young subjects with a benign phenotype of obesity. Obes. Silver Spring Md 19(8): 1684-1689. doi:10.1038/oby.2010.342.

Harris, S.S., Pittas, A.G., and Palermo, N.J. 2012. A randomized, placebo-controlled trial of vitamin D supplementation to improve glycaemia in overweight and obese African Americans. Diabetes Obes. Metab. 14(9): 789-794. doi:10.1111/j.1463-1326.2012.01605.x.

Hjelmesaeth, J., Hofsø, D., Aasheim, E.T., Jenssen, T., Moan, J., Hager, H., et al. 2009. Parathyroid hormone, but not vitamin $\mathrm{D}$, is associated with the metabolic syndrome in morbidly obese women and men: a cross-sectional study. Cardiovasc. Diabetol. 8: 7. doi:10.1186/1475-2840-8-7.

Holick, M.F., Binkley, N.C., Bischoff-Ferrari, H.A., Gordon, C.M., Hanley, D.A., Heaney, R.P., et al. 2011. Evaluation, treatment, and prevention of vitamin D deficiency: an Endocrine Society clinical practice guideline. J. Clin. Endocrinol. Metab. 96(7): 1911-1930. doi:10.1210/jc.2011-0385.

von Hurst, P.R., Stonehouse, W., and Coad, J. 2010. Vitamin D supplementation reduces insulin resistance in South Asian women living in New Zealand who are insulin resistant and vitamin $D$ deficient - a randomised, placebo-controlled trial. Br. J. Nutr. 103(4): 549-555.

doi:10.1017/S0007114509992017.

Hyppönen, E., and Power, C. 2007. Hypovitaminosis D in British adults at age $45 \mathrm{y}$ : nationwide cohort study of dietary and lifestyle predictors. Am. J. Clin. Nutr. 85(3): 860-868.

Jorde, R., and Figenschau, Y. 2009. Supplementation with cholecalciferol does not improve glycaemic control in diabetic subjects with normal serum 25-hydroxyvitamin D levels. Eur. J. Nutr. 48(6): 349354. doi:10.1007/s00394-009-0020-3.

Kamycheva, E., Joakimsen, R.M., and Jorde, R. 2003. Intakes of calcium and vitamin d predict body mass index in the population of Northern Norway. J. Nutr. 133(1): 102-106.

Kamycheva, E., Sundsfjord, J., and Jorde, R. 2004. Serum parathyroid hormone level is associated with body mass index. The 5th Troms $\varnothing$ study. Eur. J. Endocrinol. Eur. Fed. Endocr. Soc. 151(2): 167172.

Kayaniyil, S., Vieth, R., Harris, S.B., Retnakaran, R., Knight, J.A., Gerstein, H.C., et al. 2011. Association of 25(OH)D and PTH with metabolic syndrome and its traditional and nontraditional components. J.

Clin. Endocrinol. Metab. 96(1): 168-175. doi:10.1210/jc.2010-1439.

Kelishadi, R., Salek, S., Salek, M., Hashemipour, M., and Movahedian, M. 2014. Effects of vitamin D supplementation on insulin resistance and cardiometabolic risk factors in children with metabolic 
syndrome: a triple-masked controlled trial. J. Pediatr. (Rio J.) 90(1): 28-34.

doi:10.1016/j.jped.2013.06.006.

Lagunova, Z., Porojnicu, A.C., Lindberg, F., Hexeberg, S., and Moan, J. 2009. The dependency of vitamin D status on body mass index, gender, age and season. Anticancer Res. 29(9): 3713-3720.

Mason, C., Xiao, L., Imayama, I., Duggan, C., Wang, C.-Y., Korde, L., et al. 2014. Vitamin D3 supplementation during weight loss: a double-blind randomized controlled trial. Am. J. Clin. Nutr. 99(5): 1015-1025. doi:10.3945/ajcn.113.073734.

Matthews, D.R., Hosker, J.P., Rudenski, A.S., Naylor, B.A., Treacher, D.F., and Turner, R.C. 1985. Homeostasis model assessment: insulin resistance and beta-cell function from fasting plasma glucose and insulin concentrations in man. Diabetologia 28(7): 412-419.

Nagpal, J., Pande, J.N., and Bhartia, A. 2009. A double-blind, randomized, placebo-controlled trial of the short-term effect of vitamin D3 supplementation on insulin sensitivity in apparently healthy, middle-aged, centrally obese men. Diabet. Med. J. Br. Diabet. Assoc. 26(1): 19-27.

doi:10.1111/j.1464-5491.2008.02636.x.

Poolsup, N., Suksomboon, N., and Plordplong, N. 2016. Effect of vitamin D supplementation on insulin resistance and glycaemic control in prediabetes: a systematic review and meta-analysis. Diabet. Med. J. Br. Diabet. Assoc. 33(3): 290-299. doi:10.1111/dme.12893.

Popkin, B.M. 2010. Recent dynamics suggest selected countries catching up to US obesity. Am. J. Clin. Nutr. 91(1): 284S-288S. doi:10.3945/ajcn.2009.28473C.

Reis, J.P., von Mühlen, D., Kritz-Silverstein, D., Wingard, D.L., and Barrett-Connor, E. 2007. Vitamin D, parathyroid hormone levels, and the prevalence of metabolic syndrome in community-dwelling older adults. Diabetes Care 30(6): 1549-1555. doi:10.2337/dc06-2438.

Salehpour, A., Shidfar, F., Hosseinpanah, F., Vafa, M., Razaghi, M., and Amiri, F. 2013. Does vitamin D3 supplementation improve glucose homeostasis in overweight or obese women? A double-blind, randomized, placebo-controlled clinical trial. Diabet. Med. J. Br. Diabet. Assoc. 30(12): 1477-1481. doi:10.1111/dme.12273.

Schindler, A.E., Ebert, A., and Friedrich, E. 1972. Conversion of androstenedione to estrone by human tissue. J. Clin. Endocrinol. Metab. 35(4): 627-630. doi:10.1210/jcem-35-4-627.

Shevde, N.K., Bendixen, A.C., Dienger, K.M., and Pike, J.W. 2000. Estrogens suppress RANK ligandinduced osteoclast differentiation via a stromal cell independent mechanism involving c-Jun repression. Proc. Natl. Acad. Sci. U. S. A. 97(14): 7829-7834. doi:10.1073/pnas.130200197.

Sukumar, D., Partridge, N.C., Wang, X., and Shapses, S.A. 2011. The high serum monocyte chemoattractant protein-1 in obesity is influenced by high parathyroid hormone and not adiposity. J. Clin. Endocrinol. Metab. 96(6): 1852-1858. doi:10.1210/jc.2010-2781.

Tanaka, Y., Castillo, L., and DeLuca, H.F. 1976. Control of renal vitamin D hydroxylases in birds by sex hormones. Proc. Natl. Acad. Sci. U. S. A. 73(8): 2701-2705. 
Vilarrasa, N., Maravall, J., Estepa, A., Sánchez, R., Masdevall, C., Navarro, M.A., et al. 2007. Low 25hydroxyvitamin $D$ concentrations in obese women: their clinical significance and relationship with anthropometric and body composition variables. J. Endocrinol. Invest. 30(8): 653-658.

Wamberg, L., Kampmann, U., Stødkilde-Jørgensen, H., Rejnmark, L., Pedersen, S.B., and Richelsen, B. 2013. Effects of vitamin D supplementation on body fat accumulation, inflammation, and metabolic risk factors in obese adults with low vitamin D levels - results from a randomized trial. Eur. J. Intern. Med. 24(7): 644-649. doi:10.1016/j.ejim.2013.03.005.

Wang, Y., Beydoun, M.A., Liang, L., Caballero, B., and Kumanyika, S.K. 2008. Will all Americans become overweight or obese? estimating the progression and cost of the US obesity epidemic. Obes. Silver Spring Md 16(10): 2323-2330. doi:10.1038/oby.2008.351.

Yach, D., Stuckler, D., and Brownell, K.D. 2006. Epidemiologic and economic consequences of the global epidemics of obesity and diabetes. Nat. Med. 12(1): 62-66. doi:10.1038/nm0106-62. 
Table 1: Anthropometric and metabolic parameters of the study participants.

\begin{tabular}{ccccc}
\hline & MHO & IRO & P value & Cohen's $d$ \\
\hline Gender (male/female) & $20 / 73$ & $17 / 48$ & 0.49 & \\
Age & $44.79 \pm 13.27$ & $40.96 \pm 13.86$ & 0.08 & 0.28 \\
Weight (kg) & $94.56 \pm 10.94$ & $100.71 \pm$ & $\mathbf{0 . 0 0 1}$ & 0.52 \\
BMI (kg/m²) & $34.57 \pm 2.69$ & $35.98 \pm 2.78$ & $\mathbf{0 . 0 0 1}$ & 0.52 \\
& $106.26 \pm 10.81$ & $109.94 \pm$ & $\mathbf{0 . 0 3 3}$ & 0.35 \\
Waist circumference (cm) & $41.29 \pm 5.87$ & $40.54 \pm 6.94$ & 0.48 & 0.12 \\
Total Fat mass (\%) & $19.97 \pm 4.24$ & $22.23 \pm 6.04$ & $\mathbf{0 . 0 0 7}$ & 0.45 \\
Fat mass trunk (kg) & $5.57 \pm 0.38$ & $5.85 \pm 1.12$ & $\mathbf{0 . 0 3 3}$ & 0.36 \\
HbAlc (\%) & $5.31 \pm 1.18$ & $5.54 \pm 1.56$ & 0.296 & 0.17 \\
Total cholesterol (mmol/liter) & $1.62 \pm 0.71$ & $1.85 \pm 0.71$ & $\mathbf{0 . 0 4 7}$ & 0.33 \\
TG (mmol/liter) & $3.28 \pm 1.04$ & $3.43 \pm 1.56$ & 0.466 & 0.12 \\
LDL (mmol/liter) & $1.30 \pm 0.33$ & $1.27 \pm 0.47$ & 0.597 & 0.07 \\
HDL (mmol/liter) & $4.87 \pm 4.75$ & $6.94 \pm 7.65$ & $\mathbf{0 . 0 4 1}$ & 0.34 \\
hsCRP (mg/liter) & 59.26 & 40.74 & 0.16 & 0.22 \\
25OHD deficiency (\%) & $19.50 \pm 8.11$ & $21.94 \pm 9.69$ & 0.111 & 0.28 \\
25OHD (nmol/liter) & $37.45 \pm 24.35$ & $31.97 \pm 13.69$ & 0.130 & 0.27 \\
PTH (ng/liter) & $2.36 \pm 0.15$ & $2.35 \pm 0.25$ & 0.650 & 0.05 \\
Calcium (nmol/liter) & $1.33 \pm 1.89$ & $1.14 \pm 0.56$ & 0.440 & 0.13 \\
Phosphorus (nmol/liter) & $1.72 \pm 0.77$ & $4.86 \pm 2.15$ & - & 2.11 \\
HOMA-IR & $6.59 \pm 1.82$ & $7.56 \pm 1.71$ & $\mathbf{0 . 0 0 1}$ & 0.55 \\
2-h glucose (mmol/liter) & $0.06 \pm 1.21$ & $-0.037 \pm 1.14$ & 0.637 & 0.08 \\
T score spine & $0.32 \pm 1$ & $0.23 \pm 0.98$ & 0.608 & 0.09 \\
T score hips & & & \\
\hline
\end{tabular}

Variables are expressed as means \pm SD unless otherwise stated. 
Table 2: Multivariate linear regression among MHO participants.

\begin{tabular}{|c|c|c|c|}
\hline & & & P Value \\
\hline \multirow[t]{6}{*}{ Outcome variable } & $25 \mathrm{OHD}$ & & 0.87 \\
\hline & Age & $0.034(0.12)$ & 0.77 \\
\hline & hsCRP (mg/liter) & $0.097(0.11)$ & 0.39 \\
\hline & $\begin{array}{l}\text { Fasting glucose } \\
(\mathrm{mmol} / \text { liter })\end{array}$ & $-0.138(0.13)$ & 0.28 \\
\hline & 2-h glucose (mmol/liter) & $-0.012(0.12)$ & 0.91 \\
\hline & Fasting insulin $(\mu \mathrm{U} / \mathrm{ml})$ & $-0.39(0.11)$ & 0.72 \\
\hline \multirow[t]{6}{*}{ Outcome variable } & PTH & & 0.55 \\
\hline & Age & $0.13(0.12)$ & 0.28 \\
\hline & hsCRP (mg/liter) & $0.14(0.11)$ & 0.21 \\
\hline & $\begin{array}{l}\text { Fasting glucose } \\
\text { (mmol/liter) }\end{array}$ & $0.030(0.13)$ & 0.81 \\
\hline & 2-h glucose (mmol/liter) & $-0.08(0.12)$ & 0.47 \\
\hline & Fasting insulin $(\mu \mathrm{U} / \mathrm{ml})$ & $0.12(0.11)$ & 0.25 \\
\hline
\end{tabular}

Data are expressed as standardized coefficients (standard errors). Age was forced in the model 
Table 3: Multivariate linear regression among IRO patients

\begin{tabular}{|c|c|c|c|}
\hline & & & P Value \\
\hline \multirow[t]{6}{*}{ Outcome variable } & $25 \mathrm{OHD}$ & & 0.051 \\
\hline & Age & $0.40(0.14)$ & 0.005 \\
\hline & hsCRP (mg/liter) & $0.01(0.12)$ & 0.92 \\
\hline & $\begin{array}{l}\text { Fasting glucose } \\
(\mathrm{mmol} / \text { liter })\end{array}$ & $-0.039(0.12)$ & 0.76 \\
\hline & 2-h glucose (mmol/liter) & $0.01(0.13)$ & 0.93 \\
\hline & Fasting insulin $(\mu \mathrm{U} / \mathrm{ml})$ & $-0.078(0.12)$ & 0.51 \\
\hline \multirow[t]{6}{*}{ Outcome variable } & PTH & & 0.18 \\
\hline & Age & $0.15(0.14)$ & 0.27 \\
\hline & hsCRP (mg/liter) & $-0.26(0.12)$ & 0.041 \\
\hline & $\begin{array}{l}\text { Fasting glucose } \\
\text { (mmol/liter) }\end{array}$ & $-0.057(0.13)$ & 0.66 \\
\hline & 2-h glucose (mmol/liter) & $0.08(0.14)$ & 0.57 \\
\hline & Fasting insulin $(\mu \mathrm{U} / \mathrm{ml})$ & $-0.024(0.12)$ & 0.84 \\
\hline
\end{tabular}

Data are expressed as standardized coefficients (standard errors). Age was forced in the model 